
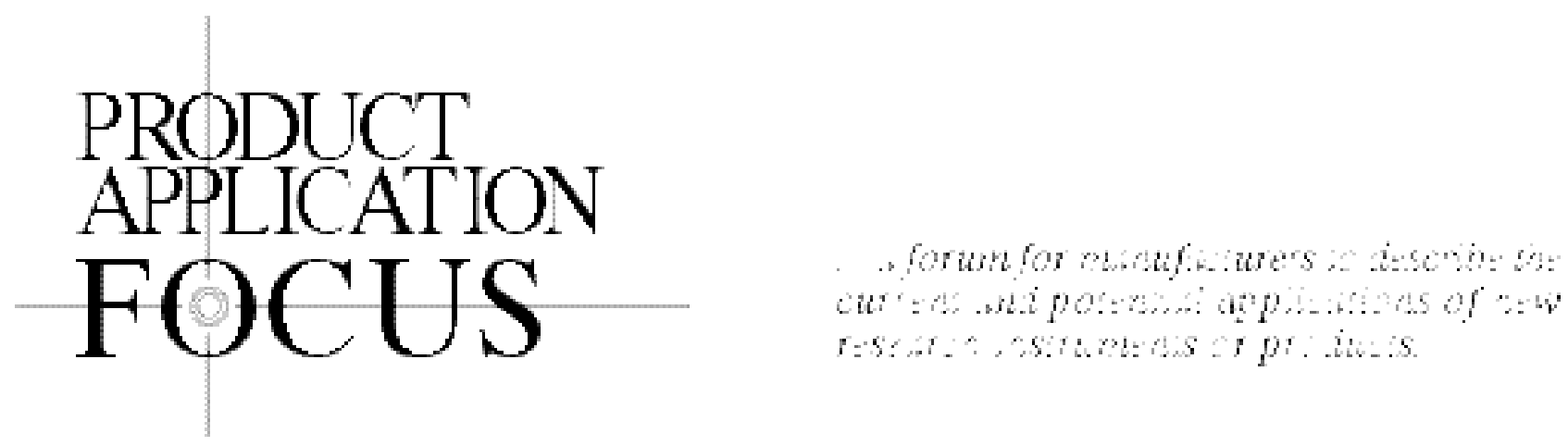

\title{
High-Throughput Array Production Using Precision Glass Syringes
}

BioTechniques 32:1360-1365 (June 2002)

\author{
J. Shieh, C. To, J. Carramao, \\ N. Nishimura ${ }^{1}$, Y. Maruta ${ }^{2}$, Y. \\ Hashimoto $^{1}$, D. Wright, H.-c. \\ Wu, and A. Azarani \\ Robbins Scientific, Sunnyvale, \\ CA, USA, ${ }^{1}$ Genetic-Lab, \\ Sapporo, and ${ }^{2}$ Lab Company, \\ Sapporo, Japan
}

ducible (precision variation of less than 5\%) from spot to spot and membrane to membrane. Using a Tango 384 system, a total of ten 6144-spot filters can be produced in approximately $25 \mathrm{~min}$, translating into a spotting speed of $2.5 \mathrm{~min} / \mathrm{membrane}$.

\section{INTRODUCTION}

Arrays have become the accepted molecular biology tool for the simultaneous analysis of thousands of genes, proteins, and compounds (1-4). DNA and protein arrays have widespread use in functional genomics research and in clinical prognostics, diagnostics, pathology, and toxicology. Compound arrays are used for drug discovery and determination of drug efficacy.

A number of printing technologies are now being widely used for the creation of arrays $(6,7)$. The most popular ones are non-contact printing with inkjet and contact printing with pins. Even though these two technologies permit the successful creation of arrays, some difficulties in implementing printing have been observed (6). Some of the complexities typically encountered are variation in spot size (due to inconsistency in the volumes printed or presence of air bubbles), splashing, evaporation of the samples during the process of delivery, clogging of the pins, and difficulties in thoroughly cleaning the spotting devices. Many of these difficulties could be circumvented by using nondisposable precision glass syringes for the printing process.

This study shows the advantages of using precision glass syringes in highthroughput liquid handling systems to create arrays of up to 6144 spots/mem brane and up to 1000 spots/slide.

\section{MATERIALS A N D METHODS}

Fluorescein (Molecular Probes, Eugene, OR, USA) was dissolved to a concentration of $10 \mu \mathrm{g} / \mathrm{mL}$ solution using a $0.1 \mathrm{M}$ Tris- $\mathrm{HCl}$ (pH 8.0) buffer. A Tango $^{\text {TM }}$ Liquid Handling System and a Hydra ${ }^{\circledR}$-PP Microdispenser (Robbins Scientific, Sunnyvale, CA, USA) equipped with 1,96 , or $384100-\mu \mathrm{L}$ stainless-steel syringes (with Teflon ${ }^{\circledR}$ coating) or syringes with DuraFlex ${ }^{\mathrm{TM}}$ (titanium alloy) needles were used for arraying purposes. Fluorescence detection was performed using a NucleoVISION $^{\mathrm{TM}}$ Imaging Workstation from Nucleotech $^{\mathrm{TM}}$ (San Mateo, CA, USA). The PCR-amplified DNA samples, which possess an M13 sequence in each fragment, were provided by GeneticLab (Sapporo, Japan). The PCR core kit was purchased from Roche Applied Science (Mannheim, Germany). The 
Table 1. Arraying Speed for Nylon Filters Using the Hydra and Tango Systems Equipped with 96 or 384 Precision Glass Syringes

\begin{tabular}{|cccc|}
\hline Number of spots & $\begin{array}{c}\text { Arraying speed } \\
\text { using } \\
\text { Hydra-PP 96 } \\
(\mathbf{m i n}) \pm \text { SD }\end{array}$ & $\begin{array}{c}\text { Arraying speed } \\
\text { using } \\
\text { Hydra-PP 384 } \\
(\mathbf{m i n}) \pm \text { SD }\end{array}$ & $\begin{array}{c}\text { Arraying speed } \\
\text { using } \\
\text { Tango 384 (min) } \\
\mathbf{\pm} \text { SD }\end{array}$ \\
\hline 96 & $3.0 \pm 0.5$ & - & - \\
384 & $11.0 \pm 0.8$ & $3.0 \pm 0.3$ & $0.5 \pm 0.1$ \\
1536 & $40.0 \pm 2.2$ & $11.0 \pm 0.5$ & $3.0 \pm 0.4$ \\
6144 & $150.0 \pm 4.2$ & $40.0 \pm 1.5$ & $13.0 \pm 1.0$ \\
The times indicated include priming, sample spotting, and the washing periods \\
for the preparation of a single membrane. Each spot corresponds to a different \\
gene. Standard deviations are shown for each speed.
\end{tabular}

amplified samples were purified using a QIAquick ${ }^{\circledR}$ PCR purification kit (Qiagen, Valencia, CA, USA). A $10 \mathrm{mM}$ Tris- $\mathrm{HCl}(\mathrm{pH} 7.5)$ buffer was used as blank in contamination studies. The Biodyne $^{\mathrm{TM}}$ Plus membrane, $0.45 \mu \mathrm{M}(8$ $\times 12 \mathrm{~cm}$ ), was purchased from Pall (East Hills, NY, USA). FAST ${ }^{\mathrm{TM}}$ and $\mathrm{CAST}^{\mathrm{TM}}$ microarray slides were purchased from Schleicher \& Schuell BioScience (Keene, NH, USA). ArraySlides (silanated) and MaxiSorp ${ }^{\mathrm{TM}}$ 96-plates were provided by Nalge-Nunc International (Roskilde, Denmark).

\section{The Tango Liquid Handling System}

The Tango system incorporates 1, 96 , or 384 nondisposable precision glass syringes arrayed in standard Society for Biomolecular Screening (SBS) microplate spacing. Its stage is composed of 12 nests. During all analyses for this study, one nest was dedicated to the wash module, one nest to a 96- or 384-well PCR plate (called the source plate), and 10 nests to nylon membranes, which were placed on a vacuum manifold. The vacuum manifold holds the membrane in position and reduces diffusion, thus concentrating each sam ple and reducing its diameter. The source plates and the membranes (placed in a vacuum manifold) could be stacked in the Tango Plate Stacker and be removed or placed onto the stage by the plate stacker's rotational gripper.

Because nondisposable glass syringes are used for all spotting, it is crucial to follow an efficient syringecleaning procedure for the inhibition of carryover contamination (Robbins Ap- plication Note 10; http://www.robsci. com/hug.html). After each spotting operation, the syringes were washed in the Tango wash module with $20 \mu \mathrm{L}$ of water for six wash cycles (one wash cycle is defined as an aspiration and a dispense; in this instance, the wash volume was set at $20 \mu \mathrm{L}$ ).

\section{The Hydra Automated Dispensing System}

The Hydra-PP Microdispenser is equipped with nondisposable syringes, a computer-controlled plate-positioning stage, and an automated syringe washing system (8). The stage is composed of two nests. In this study, one nest was dedicated to the source plate and the other nest was dedicated to a vacuum manifold containing a nylon filter. After every spotting operation with the Hydra-PP system, the syringes were washed in three wash steps (a wash step is defined as a predetermined number of wash cycles that is performed before the wash solution is replaced with fresh solution) of three wash cycles each, with each cycle having a wash volume of $20 \mu \mathrm{L}$ water (Robbins Application Note 5; http:// www.robsci.com/hug.html).

\section{Supplemental Wash Procedures for Tango and Hydra Systems}

When the Tango or Hydra systems were used for dispensing higher concentrations of DNA ( $\geq 100 \mathrm{ng} / \mu \mathrm{L})$, the washing procedure was modified to include a one-time rinse with $2 \%$ bleach, followed by multiple rinses in water be- fore performing blotting. After the last use of the microdispenser for the day, in addition to the above washes, the syringes were washed in Coulter ${ }^{\circledR}$ Clenz (Beckman Coulter, Fullerton, CA, USA) for three cycles, soaked in it for $30 \mathrm{~min}$, and then washed with water for three cycles. Finally, the head was washed with $100 \%$ ethanol for two cycles, and the syringes were emptied and dried overnight.

\section{Isolation of RNA, Preparation of Probes, and Detection}

For nylon filters, PolyA-RNA isolation and biotin-labeled probe preparation were performed using a Toyobo Array Kit (Toyobo, Tsuruga, Japan). Hybridization (using a GeneNavigator cDNA array system from Toyobo) was performed following the manufacturer's instructions. Signals were detected using a chemiluminescence kit (Imaging High $^{\mathrm{TM}}$; Toyobo) and a Fluor-S ${ }^{\circledR}$ MAX MultiImager System (Nippon BioRad ${ }^{\circledR}$ Laboratories, Tokyo, Japan) (5).

For slides, all spotting, probe preparation, and hybridization procedures were performed according to the manufacturer's instructions.

\section{RESULTS}

\section{Arraying Speed}

Using a Tango or Hydra system equipped with 1,96, or 384 precision glass syringes arrayed in microplate spacing, $50-300 \mathrm{~nL}$ of a $10 \mu \mathrm{g} / \mathrm{mL}$ fluorescein solution or 0.1-5 ng PCR-am plified human housekeeping and cancer-related genes were spotted onto nylon membranes. These compact DNA filters contain $96,384,1536$, or 6144 spots, with each spot corresponding to a different gene. The speeds of the arraying process for DNA mem branes were determined and are reported in Table 1. The arraying times include the time required for the processes of priming (trial dispensing), spotting, and washing. To produce a 384-spot membrane, for example, using a Hydra-PP equipped with 96 syringes and a 96-well source plate, the source plate had to be changed four times. To prevent carryover contamina- 
tion, the syringes had to be washed four times. This process takes a total of 11 min. To produce a similar membrane (with 384 spots) using a Hydra-PP equipped with 384 syringes, the same procedure takes approximately $3 \mathrm{~min}$ because only one wash step is required. To produce higher-density membranes of 6144 spots, it is much more efficient to use the fully automated highthroughput Tango system. With the Tango system, it takes only $13 \mathrm{~min}$ to spot one membrane with 6144 DNA spots. As the Tango stage is composed of 12 nests, with one nest dedicated to the wash module, one nest to the source plate, and 10 nests to nylon membranes, a total of ten 6144-spot membranes can be produced in $25 \mathrm{~min}(2.5$ min/6144-spot membrane). Furthermore, because generally genes are spotted in duplicates on arrays (to validate reproducibility), these spotting times can be reduced by half since the num- ber of washes required is cut by half. Therefore, a 6144-spot membrane (3072 genes in duplicate) can be produced in approximately $1 \mathrm{~min}$ on the Tango system.

\section{Spot Uniformity and Reproducibility}

Before using the Hydra and Tango systems for spotting, the uniformity and consistency of the volumes dispensed across the arrays of syringes on the systems were determined by the $\mathrm{CV}$ for specific dispensing volumes (Robbins Application Note 6; http://www. robsci. com/hug.html). A high uniformity for dispensing volumes of 50-300 nL used in the arraying assays was evident, with CVs of less than 5\%. Next, various DNA, fluorescein-, and protein-spotted mem branes and slides were prepared with these precision glass syringes. The uniformity in spot size and the consistency in the quantity of the samples dispensed are evident from the chemiluminescence and fluorescence images in Figure 1, A-C. The size of the spots created by precision glass syringes was highly uniform and reproducible from spot to spot and membrane to membrane. This is shown in Figure 1D, in which two identical membranes containing 560 different genes in duplicate were created using a Hydra system. Using either system, up to 6144 spots could be spotted onto membranes and up to 1000 spots onto slides, with the spot diameter as small as $580 \mu \mathrm{m}$ and a spot-to-spot distance of $406 \mu \mathrm{m}$.

\section{Cross-Contamination}

Following a proper washing procedure ensured the elimination of sampleto-sample carryover contamination. This is shown in Figure 2, in which a membrane containing an alternate of PCR-amplified genes ( $\beta$-actin and 


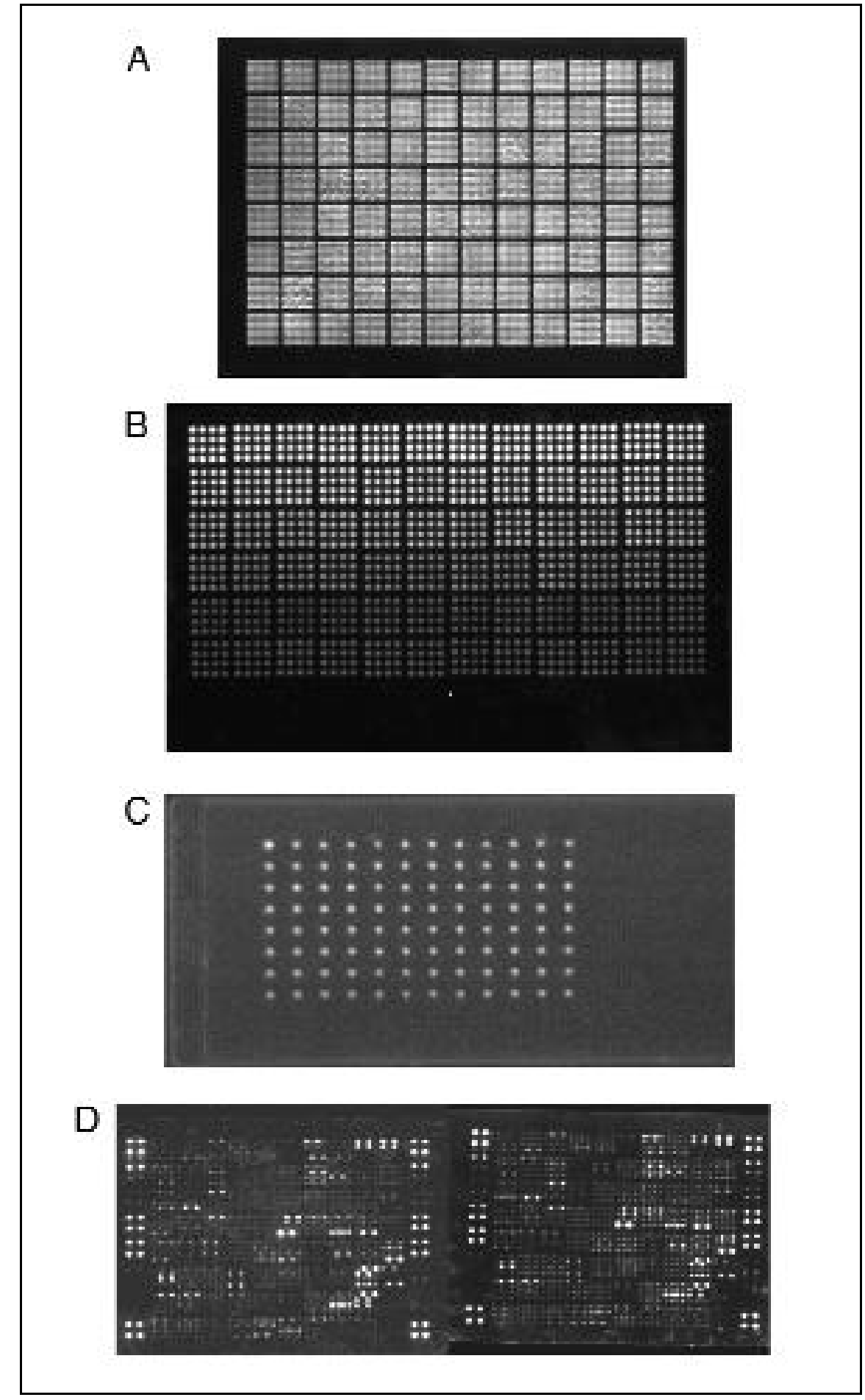

Figure 1. Arrays produced by precision glass syringes. (A) A 6144-spot DNA membrane prepared by Hydra-PP equipped with 96 syringes (Hydra-PP 96). Gene: housekeeping gene G3PDH (0.1 ng each spot). Spotting volume: $100 \mathrm{~nL}$. Probe: M13 (the PCR-amplified G3PDH cDNA had a built-in M13 sequence). Detection: chemiluminescence. (B) A 1152-spot DNA membrane prepared by Hydra-PP 96. Gene: housekeeping gene $\beta$-actin. The spots in the first row contain $5 \mathrm{ng}$ DNA each. The following rows are at 1/2,1/4, 1/8, and 1/16 dilutions. The last two rows are at 1/16 dilution. Spotting volume: $200 \mathrm{~nL}$. Probe: M13 (the PCR-amplified $\beta$-actin cDNA had a built-in M13 sequence). Detection: chemiluminescence. (C) A 96-spot fluorescein slide prepared by the Tango 1-channel (single-syringe) head system. Sample: fluorescein $(10 \mu \mathrm{g} / \mathrm{mL})$. Spotting volume: $50 \mathrm{~nL}$. Detection: fluorescence. (D) Two identical 1536-spot filters prepared by Hydra-PP system. Sample: 560 different genes spotted in duplicate $(5 \mathrm{ng})$. Spotting volume: $100 \mathrm{~nL}$. Probe: cancer cell line cDNA. Detection: chemiluminescence.
G3PDH) and $10 \mathrm{mM}$ Tris-HCl buffer as blank (containing no DNA sample) spotted in 20 rows was produced. As indicated, no carryover contamination is observed between spotted DNA sam ples and buffer spots.

\section{Dispense Performance with Protein Arrays}

Protein arrays were prepared using a Tango system equipped with 1,96 , or 384 syringes. BSA-fluorescein conjugate solutions from $50 \mu \mathrm{g} / \mathrm{mL}$ to 1 $\mathrm{mg} / \mathrm{mL}$ were spotted onto coated slides or onto Nunc-Immuno ${ }^{\mathrm{TM}}$ MaxiSorp 96well plates (the plates have a charged polystyrene surface with high binding capacity for proteins; Nalge-Nunc International) in a $3 \times 3$ pattern (Figure 3 ). When spotting BSA solutions, a dis-

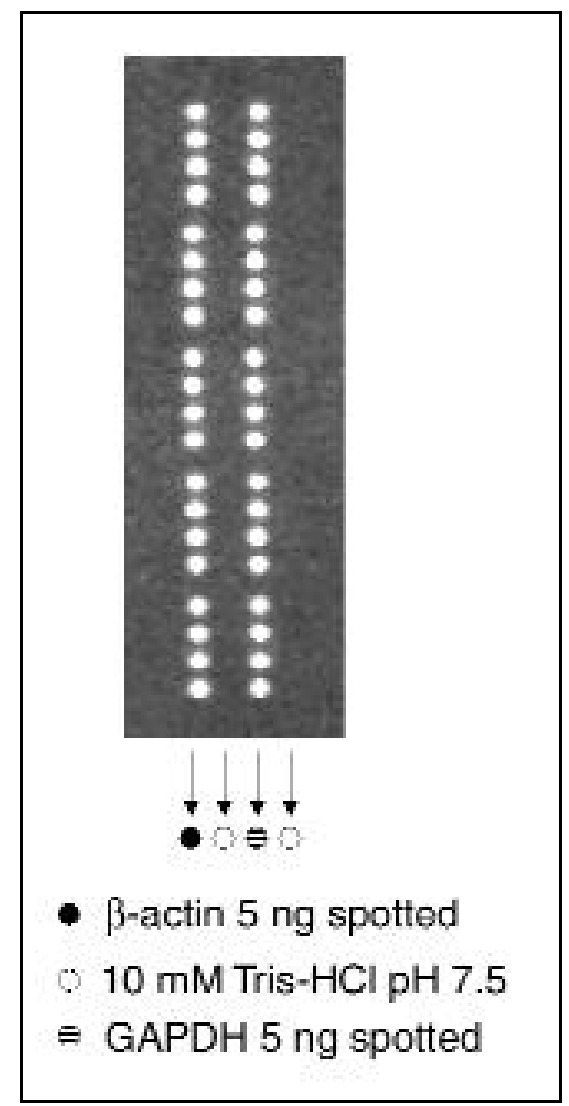

Figure 2. Carryover studies on a membrane prepared by the Hydra-PP system. Sample: $\beta$ actin $(5 \mathrm{ng}), 10 \mathrm{mM}$ Tris-HCl (pH 7.5) buffer as blank, and G3PDH (5 ng). The pattern is $\beta$-actin fragment, $10 \mathrm{mM}$ Tris-HCl buffer, G3PDH (5 ng), $10 \mathrm{mM}$ Tris-HCl buffer, repeated in 20 rows. Spotting volume: $100 \mathrm{~nL}$. Probe: M13 (the PCR cDNA fragments had a built-in M13 sequence). Detection: chemiluminescence. 


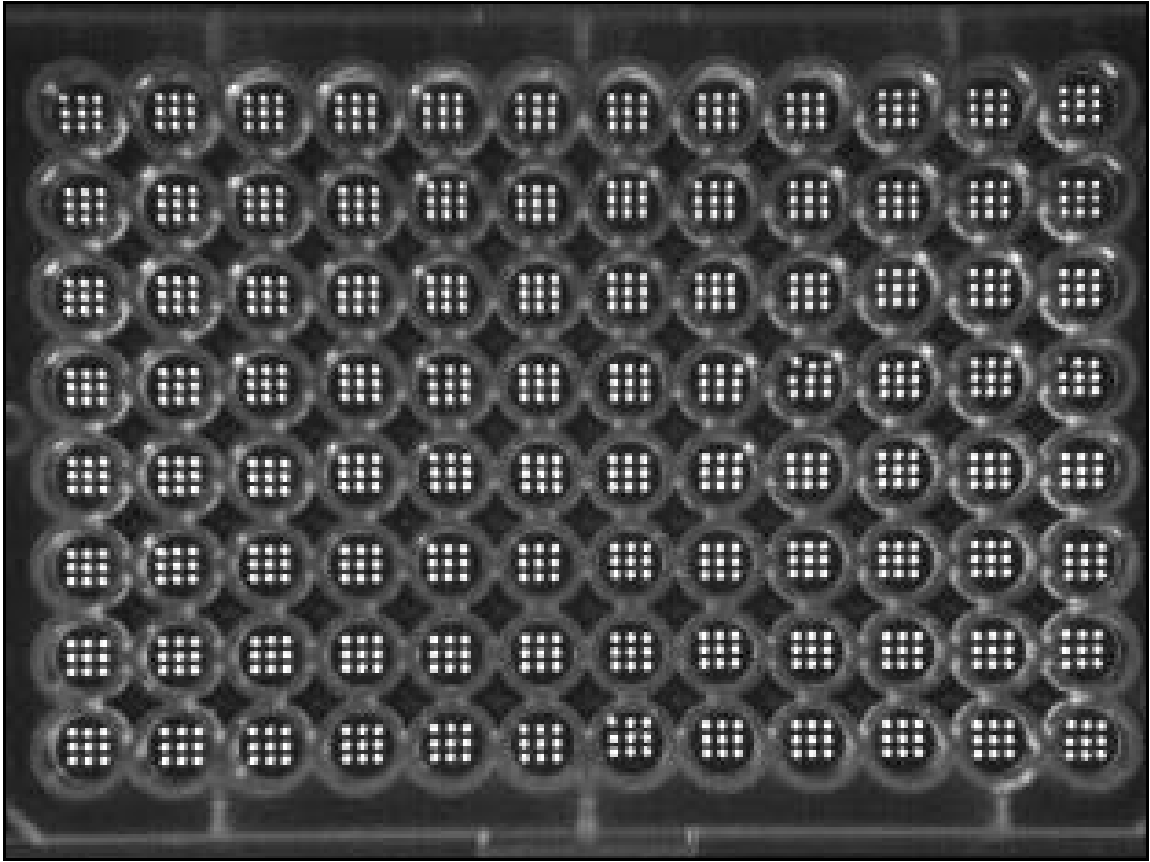

Figure 3. An 864-spot protein slide prepared by Tango 96. Protein: BSA-fluorescein $(50 \mu \mathrm{g} / \mathrm{mL})$. Spotting volume: $100 \mathrm{~nL}$. Detection: fluorescence.

pensing performance equal to those achieved when spotting nucleic acids or organic compounds (such as fluorescein) was observed.

\section{DISCUSSION}

The Tango and Hydra systems incorporate nondisposable precision glass syringes that offer a new type of printing technology free of disposable tips, pins, or inkjets. These syringes offer a reliable and accurate method of creating highly reproducible and uniform DNA and protein arrays. Glass syringes can be used to dispense volumes as low as $50 \mathrm{~nL}$ with very high precision (in the order of $95 \%$ ). As a consequence, the size of the spots created by precision glass syringes is very consistent and reproducible from spot to spot and membrane to membrane.

Precision glass syringes are inexpensive, simple to operate, robust, and easily replaceable. Since samples do not evaporate or dry once inside the syringes, there is no need for humidification. Consequently, the printed samples dry quickly and sufficiently without spreading or dispersing onto the printing surfaces.

The inside diameter of syringes used in this study was approximately 230 $\mu \mathrm{m}$. Following a proper syringe washing procedure, no clogging of syringes or sample cross-contaminations were observed. Furthermore, the syringes can be siliconized to prevent the buildup of air bubbles. With inkjet and pin technologies, bubbles have been reported to create inconsistencies in the volumes printed, causing spot variations. In this study, the sizes of the spots printed by syringes varied from 400 to $600 \mu \mathrm{m}$. With these spot sizes, it was observed that the quantity and the quality of the printed spots were not affected by dust. Therefore, printings were performed in a typical laboratory room instead of a clean room. As a consequence, a significant reduction in operation expenses was achieved.

Other difficulties typically encountered in implementing non-contact printing with inkjet or contact printing with pin technologies-such as difficulties in thoroughly cleaning the spotting devices, the drying of samples during the process of delivery, shearing of DNA samples, variation in spot size (due to inconsistencies in the volumes printed), and the so-called "donutshaped" effects-were not observed when precision glass syringes were used for arraying.

\section{CONCLUSION}

With a dispensing precision variation of less than $5 \%$ and a spotting speed of less than $25 \mathrm{~min} /$ ten 6144 -spot filters and with no sign of cross-contamination, precision glass syringes in high-throughput liquid dispensers such as the Hydra and Tango systems offer an accurate, fast, reliable, and cost-effective means of creating DNA, protein, and compound arrays.

\section{REFERENCES}

1.Emili, A.Q. and G. Cagney. 2000. Largescale functional analysis using peptide or protein arrays. Nat. Biotechnol. 18:393-397.

2.Lockhart, D.J. and E.A. Winzeler. 2000. Genomics, gene expression and DNA arrays. Nature 405:827-836.

3.Lovett, R.A. 2000. Toxicologists brace for genomics revolution. Science 289:536-537.

4.Moody, M.D., S.W. Van Arsdell, K.P. Murphy, S.F. Orencole, and C. Burns. 2001. Array-based ELISAs for high-throughput analysis of human cytokines. BioTechniques $31: 186-194$.

5.Okuno, K., M. Yasutomi, N. Nishimura, T. Arakawa, M. Shiomi, J.I. Hida, K. Ueda, and K. Minami. 2001. Gene expression analysis in colorectal cancer using practical DNA array filter. Dis. Colon Rectum 44:295299.

6.Schena, M. 2000. Microarray Biochip Technology. Eaton Publishing, Natick, MA

7.Schena, M. 1999. DNA Microarrays: A Practical Approach. Oxford University Press, New York.

8.Stanchfield, J., D. Wright, S. Hsu, M. Lam sa, and A. Robbins. 1996. Precision 96-channel dispenser for microchemical techniques. BioTechniques 20:292-296.

Address correspondence to:

Dr. Arezou Azarani

Robbins Scientific Corporation

1250 Elko Drive

Sunnyvale, CA 94089-2213, USA

e-mail:aazarani@robsci.com
For reprints of this or any other article, contact Reprints@BioTechniques.com 